\title{
Intraoperative infusion of dexmedetomidine reduces postoperative analgesic requirements
}

\section{Kalinoglou S. ${ }^{1}$, Michaloliakou C'., Papadopoulou T.', Kalantzi N. ${ }^{1}$, Tsaroucha A. ${ }^{2}$, Siafaka I. ${ }^{2}$}

\section{Metaxa Cancer Hospital, Dept of Anaesthesiology \& Pain Medicine, Piraeus, Greece}

2. Aretaieio Hospital, Medical School, University of Athens, Dept of Anaesthesiology, Pain Relief and Palliative Care Unit, Athens, Greece

Introduction: Dexmedetomidine (Dex) is a highly selective $\alpha 2$-agonist with sedative and analgesic effects. Dex has analgesic-sparing effects and in addition has not been associated with respiratory depression. These properties make it an ideal perioperative medication for painful surgical procedures. ${ }^{1}$

Purpose: This prospective, randomized, double-blind pilot study was designed to assess whether intraoperative infusion of Dex provides effective postoperative analgesia after total abdominal hysterectomy (TAH).

After institutional approval Material of the Study was composed of $\mathbf{2 2}$ women who signed informed consent \& respected following criteria:

\begin{tabular}{|l|l|}
\hline \multicolumn{1}{|l|}{ Inclusion Criteria } & \multicolumn{1}{|c|}{ Exclusion Criteria } \\
\hline & $\begin{array}{l}\text { Inability to use the PCA } \\
\text { device }\end{array}$ \\
- $\begin{array}{l}\text { Renal or hepatic dysfunction } \\
\text { regular TAH }\end{array}$ & $\begin{array}{l}\text { Cardiac failure or valvular } \\
\text { heart disease }\end{array}$ \\
- ASA I-II & $\begin{array}{l}\text { Long term use of certain } \\
\text { drugs ( } \beta \text {-blockers, analgesics, } \\
\text { sedatives) }\end{array}$ \\
- $35-67 \mathrm{~kg}$ & $\begin{array}{l}\text { Alcohol abuse and heavy } \\
\text { smoking }\end{array}$ \\
\end{tabular}

- Double-blind

\section{METHODS}

- Randomly assigned to two groups

- Treatment group D ( $\mathrm{n=11)}$ : received Dex $1 \mu \mathrm{g} \cdot \mathrm{kg}^{-1}$ iv, 15 min after induction of anaesthesia, followed by a continuous infusion at a rate of $0.4 \mu \mathrm{g} \cdot \mathrm{kg}^{-1} \cdot \mathrm{hr}^{-1}$ throughout the operation.

- Placebo group $(n=11)$ received the same bolus volume and infusion of placebo ( $0.9 \%$ saline)

- Induction of anaesthesia was the same for all pts

- Maintenance of anaesthesia with desflurane, $\mathrm{O}_{2} / \mathrm{N}_{2} \mathrm{O}\left(\mathrm{FiO}_{2}=0.4\right)$ around a BIS of 40 .
We recorded:

- Time to extubation,

- First analgesic request

- Heart rate (HR) $]$ intraop. every $15 \mathrm{~min}$

- MAP, SAP, DAP; $\left.\mathrm{SpO}_{2}\right\rfloor$ \& postop. for $48 \mathrm{~h}$

Pts stayed in PACU for $2 \mathrm{~h}$, where they received a bolus dose of tramadol when Verbal Rating Pain Score (VRPS) $\geq 4$. Analgesia was followed by the use of PCA with $15 \mathrm{mg}$ tramadol bolus and lock-out $10 \mathrm{~min}$.

- Cumulative tramadol consumption

- Assessment of pain,

- at rest VRPS (0-10)

- in movement Prince Henry Pain Scale $(0-4)^{2}$

- Sedation with Ramsay scale (0-4)

- Nausea with Likert scale (0-3)
At $0,15,30,45,90,120$

min in PACU

and $4,8,16,24,48 \mathrm{~h}$ after surgery at the ward

\section{RESULTS AND DISCUSSION}

$\checkmark$ Mean age: $50 \pm 8.21$

$\checkmark$ Mean weight $73 \pm 12.59$

$\checkmark$ The 2 groups were similar regarding the demographics, the mean time to extubation from anaesthesia, the nausea and sedation scores at all times

$\checkmark$ VPRS in the first 90 min was significantly $\downarrow$ in group $\mathrm{D}=2.9 \pm 1.8$ vs $\mathrm{P}=5.9 \pm 0.8$ ( $\mathrm{P}=0.001$, $\mathrm{t}$-test)

$\checkmark$ The time of first analgesic request was significantly $\uparrow$ in group $D=192.45 \pm$ vs $P=19 \pm 30 \min (P<0.001$ MannWhitney Test)

$\checkmark$ The total tramadol consumption was significantly $\downarrow$ in D at 24 and $48 \mathrm{~h}, 262.2 \pm 102$ and $336.8 \pm 146.6 \mathrm{mg}$ vs $349.4 \pm 115$ and $485 \pm 165 \mathrm{mg}$ in group $P$ respectively.

Conclusion: Continuous i.v. Dex during abdominal hysterectomy significantly reduced postoperative tramadol consumption and postponed the time of first analgesic request. 